\title{
Properties of the Composition Based on Modified Polyethylenes
}

\author{
Shixaliyev Kerem Sefi \\ Department of "Organic Substances and Technology of Macromolecular Compounds" Chemical-Technological Faculty, Azerbaijan State \\ University of Oil and Industry, Baku, Azerbaijan
}

\section{Email address:}

kerem shixaliyev@mail.ru

\section{To cite this article:}

Shixaliyev Kerem Sefi. Properties of the Composition Based on Modified Polyethylenes. American Journal of Chemical Engineering. Vol. 7, No. 3, 2019, pp. 90-101. doi: 10.11648/j.ajche.20190703.12

Received: July 15, 2019; Accepted: August 13, 2019; Published: October 20, 2019

\begin{abstract}
The subject of this paper is to study the properties of compositions based on a modified polyethylene and a thermoplastic polyolefin structural features. As a result of the modification of polyethylene, the high elasticity of the material grows, which outwardly makes this polymer similar in complex to the physico-mechanical properties of rubber. The calculations made allowed us to estimate the parameters of the observed thermal transitions and to assign them to the mobility of specific elem ents of the structure.
\end{abstract}

Keywords: Polyethylene, Oil, Gasoline, Strength, Temperature, Swelling, Fuel, Rheology

\section{Introduction}

\subsection{Structural Features of Polyolefin Thermoplastic Elastomers}

Polyolefin thermoplastic elastomers were obtained on the basis of ethylene-propylene elastomers and high-density polyethylene by two methods, in the first case sulfurcontaining compounds (altaks, sulfur) were used as the modifying agent, in the second-MPC.

"A" series thermoplastic elastomers were obtained by combining the initial polymer components in the melt on the rollers at a roll temperature of $433 \div 4530 \mathrm{~K}$ with a gap of $\sim$ $0.2 \mathrm{~mm}$ between them. After melting the crystalline thermoplastic, EPDM and structuring agents were added. To achieve a good homogenization, the rolling was carried out for 25 minutes.

The composition formulation had the following composition (parts by weight): EPDM-100; HDPE-10 $\div 80$; dicumyl peroxide 1-2.

The thermoplastic elastomers of the " $\mathrm{B}$ " series were obtained in the same way as the "A"-type thermoplastic elastomers, according to the following formulation (wt.): EPDM-100; HDPE-10 $\div 80$; altaks 1.8; sulfur-2.0.

\subsection{The Effect of Aggressive Liquids on the Basic Properties of Polyethylene}

When operating polymeric materials, it is necessary consider the influence of aggressive liquids on their basic properties. The stability of HDPE and its stabilized samples for various types of oils and petroleum products has been studied. In this connection, it was important to clarify the effect of stabilizers on swelling processes in petroleum products [1-7].

Four types of oil have been researched: Balakhan's, Shirvan's, Turkmen's, and coal oils, as well as A-72, A-93, diesel fuel "L" as petroleum products. The samples of HDPE were immersed in the form of plates $1 \mathrm{~mm}$ thick in hermetic glassware, where they were kept for a long time at room temperature- $200^{\circ} \mathrm{C}$. Significant deterioration of strength properties is observed in samples after 12 months of contact with Balakhan oil; comparatively worse properties are shown by HDPE samples containing TU and Thioalkofen-MBP, both in its deformation and strength properties. The original HDPE retains its properties for a long period. The samples containing stabilizers Diafen-NN (N, N'-Di-2-naphthalenyl1,4-benzenediamineand) exhibit high stability. 


\section{Result}

Table 1 shows the results of the swelling of HDPE and its stabilized compositions in various petroleum and petroleum products. Samples in a relatively greater degree swell in petroleum products such as A-72, A-93 gasoline. As the contact time increases, the degree of swelling increases. Significant swelling is observed in the first months, then the swelling rate slows down, and in some cases does not change. Analyzing the data, it can be seen that the HDPE samples stabilized by Diafen-NN and Benzon-00 and Tioalkofen-MBP swell slightly. This, probably, is related to the spherulitic structure of these HDPE samples, which exerts a resistance to the diffusion of petroleum products into the polymer volume.

In oils, swelling occurs to a lesser extent. The exception is coal oil, in which the swelling of the initial HDPE in 12 months reaches $8.4 \%$. In the presence of the Diafen-NN stabilizer, the swelling for this period does not exceed $2.16 \%$. And in this case, the presence of the stabilizer gives a positive effect, which consists in reducing the degree of swelling in various oils and petroleum products. Important in this case is the change in the physico-mechanical properties of the samples after prolonged exposure to the above media.

Table 1. The degree of swelling of HDPE and its stabilized samples in oil and fuels at a temperature of $+200 \mathrm{C}$, mass \%.

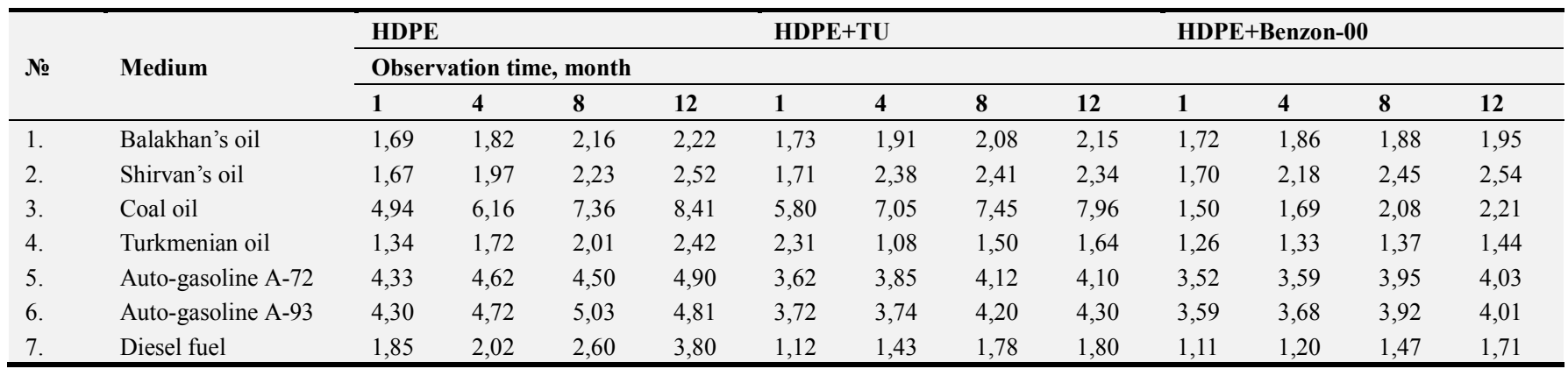

Table 1. Continued.

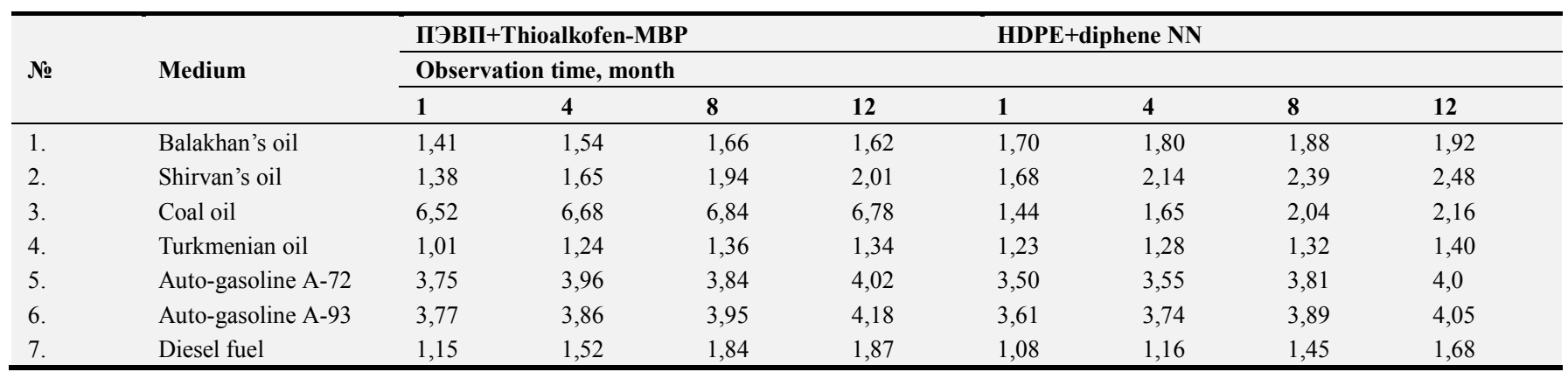

Depending on the field, oil has a tangible effect on the physical and mechanical properties (Table 2) HDPE.

Table 2. Influence of oils from various fields on the physico-chemical properties of HDPE and its stabilized compositions after 12 months.

\begin{tabular}{|c|c|c|c|c|c|c|c|c|c|c|c|}
\hline \multirow{2}{*}{ № } & \multirow{2}{*}{ Oil } & \multicolumn{2}{|c|}{ HDPE } & \multicolumn{2}{|c|}{ HDPE+Benzon-00 } & \multicolumn{2}{|c|}{ HDPE+Dephene-NN } & \multicolumn{2}{|c|}{ HDPE+TU } & \multicolumn{2}{|c|}{ HDPE+Thialcophene MBP } \\
\hline & & $\sigma_{\mathrm{p}}$ & $\varepsilon, \%$ & $\sigma_{\mathrm{p}}$ & $\varepsilon, \%$ & $\sigma_{\mathrm{p}}$ & $\varepsilon, \%$ & $\sigma_{\mathrm{p}}$ & $\varepsilon, \%$ & $\sigma_{\mathrm{p}}$ & $\varepsilon, \%$ \\
\hline 1. & İnitial properties & 370 & 300 & 375 & 320 & 394 & 420 & 367 & 300 & 454 & 370 \\
\hline 2. & Shirvan's oil & 382 & 350 & 405 & 850 & 405 & 350 & 350 & 210 & 370 & - \\
\hline 3. & Turkmenian oil & 395 & 350 & 320 & 800 & 370 & 870 & 380 & - & 206 & 150 \\
\hline 4. & Coal oil & 368 & 400 & 390 & 730 & 350 & 300 & 340 & 250 & 352 & - \\
\hline 5. & Balakhan's oil & 342 & 650 & 338 & 750 & 340 & 900 & 318 & 195 & 295 & 200 \\
\hline
\end{tabular}

\subsection{Dielectric Properties of Stabilized Polyethylenes}

The use of stabilizers in modern polymer processing technology plays an important role: they are not only inhibitors, but also in some cases structure-forming agents and substantially improve the performance properties of polymers [3-10].

When choosing stabilizers for polyethylenes, we were guided by the results of studies on the inhibitory activity of a number of compounds in the thermal oxidation of HDPE, and we selected: a mixture of amines (diphene+benzon), thioalkofen MBP.

The choice of the optimum amount of stabilizer was made by comparing the dielectric properties of HDPE measured at different frequencies (Table 3). 
Table 3. The effect of stabilizers on the dielectric properties of HDPE (SD).

\begin{tabular}{|c|c|c|c|c|c|c|c|c|}
\hline \multirow{3}{*}{$\begin{array}{l}\text { № of the } \\
\text { samples }\end{array}$} & \multirow{3}{*}{$\begin{array}{l}\text { Melting index, } \\
\text { g/10 min, } \mathbf{J}\end{array}$} & \multirow{3}{*}{ Ash content, $\% \mathrm{Z}$} & \multirow{3}{*}{ Stabilizer } & \multirow{3}{*}{$\begin{array}{l}\text { Stabilizer content } \\
\text { weight. } \%\end{array}$} & \multicolumn{4}{|c|}{ Dielectric properties } \\
\hline & & & & & \multicolumn{2}{|l|}{$\varepsilon^{\prime}$} & \multicolumn{2}{|l|}{$\operatorname{tg} \delta \times 10^{4}$} \\
\hline & & & & & $\mathrm{f}=10^{6} \mathrm{~Hz}$ & $\mathrm{f}=10^{1} \mathrm{~Hz}$ & $\mathrm{f}=10^{6} \Gamma \mathrm{Hz}$ & $\mathrm{f}=10^{10} \mathrm{~Hz}$ \\
\hline 1 & 6,3 & 0,08 & Thioalkofen MBP & 0,1 & 2,37 & 2,32 & 2,1 & 2,2 \\
\hline 2 & $-\ll-$ & $-\ll-$ & $-\ll-$ & 0,2 & 2,34 & 2,33 & 3,1 & 3,2 \\
\hline 3 & $-\ll-$ & $-\ll-$ & $-\ll-$ & 0,3 & 2,44 & 2,35 & 4,5 & 4,7 \\
\hline 4 & $-\ll-$ & $-\ll-$ & $-\ll-$ & 0,4 & 2,45 & 2,35 & 6,0 & 6,0 \\
\hline 5 & $-\ll-$ & $-\ll-$ & $-\ll-$ & 0,5 & 2,47 & 2,37 & 7,14 & 7,4 \\
\hline 6 & $-\ll-$ & $-\ll-$ & $-\ll-$ & 1,0 & 2,49 & 2,37 & 8,9 & 8,9 \\
\hline 7 & 5,3 & 0,07 & Amines' mixture & 0,2 & 2,37 & 2,31 & 3,4 & 3,4 \\
\hline 8 & $-\ll-$ & $-\ll-$ & $-\ll-$ & 0,1 & 2,31 & 2,31 & 2,7 & 2,7 \\
\hline 9 & $-\ll-$ & $-\ll-$ & $-\ll-$ & 0,3 & 2,37 & 2,27 & 4,9 & 4,9 \\
\hline 10 & 6,3 & $-\ll-$ & $-\ll-$ & 0,4 & 2,30 & 2,30 & 6,0 & 6,0 \\
\hline 11 & 5,3 & $-\ll-$ & $-\ll-$ & 0,5 & 2,30 & 2,30 & 8,8 & 8,8 \\
\hline
\end{tabular}

An analysis of the results shows that thioalkofen MBP and a mixture of amines can be introduced into HDPE in an amount of up to $0.2 \%$. At the same time, dielectric parameters remain within the limits of technical requirements. An additional assessment of the stabilizing effect of these stabilizers on HDPE was carried out in the study of atmospheric and artificial aging.

The aging process was carried out on an IP-1-3 westermeter and under atmospheric conditions. The periodic part of the samples was removed and monitored for a change in their appearance, color, melt index, strength dielectric parameters. Atmospheric aging was carried out in the climatic zone of Absheron in the period June-September, which is the richest in solar radiation.

Despite the saturation, there are abnormal structural groups in the HDPE chain, which facilitates the oxidation process under the influence of ultraviolet irradiation. HDPE contains carbonyl groups formed as a result of direct oxidation during aging. In addition, the number of methyl groups in the polymer was $7-15$ per 1000 carbon atoms.

In HDPE, there are also at least three types of carboncarbon bonds. These are terminal $\left(\mathrm{R}-\mathrm{CH}=\mathrm{CH}_{2}\right)$, Internal (R$\mathrm{CH}=\mathrm{CH}-\mathrm{R}$ ) and lateral $\mathrm{R}$ " $\mathrm{R}^{\prime}>\mathrm{C}=\mathrm{CH}$ bonds. The total amount of unsaturation of HDPE subjected to that atmospheric aging was from 1 to $3 \mathrm{~g} \backslash$.

The formation of carbonyl groups, i.e. the appearance of structural damage in HDPE affects the increase in dielectric losses. Under these conditions, the permittivity practically does not change. As can be seen, in the initial aging period, the melt index decreases from $5.3 \mathrm{~g} / 10 \mathrm{~min}$ to 2.6 , and then increases almost linearly, slightly exceeding the original value by the end of the second month.

The obtained data indicate the simultaneity of the processes of destruction and structuring, with structuring dominating at first, accompanied by intermolecular crosslinking, which is in full accordance with a decrease in the melt index and a slight increase in strength. The increase in the melt index indicates destructive processes, accompanied by a decrease in MW polyethylene. The latter circumstance easily explains the total loss of strength indicators. Thus, the tensile strength in the first 20 days of exposure changes insignificantly, and in the next 10 days it decreases to 25.0 $\mathrm{MPa}$, and in the first week of the second month HDPE becomes practically brittle, as indicated by a significant loss of elongation, from $800 \%$ before aging, up to $250 \%$ (Figure $1)$.

In the process of aging for 90 days, samples of unstabilized HDPE changed their color from white to matte white.

The change in color indicates once again the structural changes that occur during the aging of the polymer.

The aging of HDPE, stabilized with a $0.2 \%$ mixture of amines and thioalkophen, is shown in Figures 1-4.

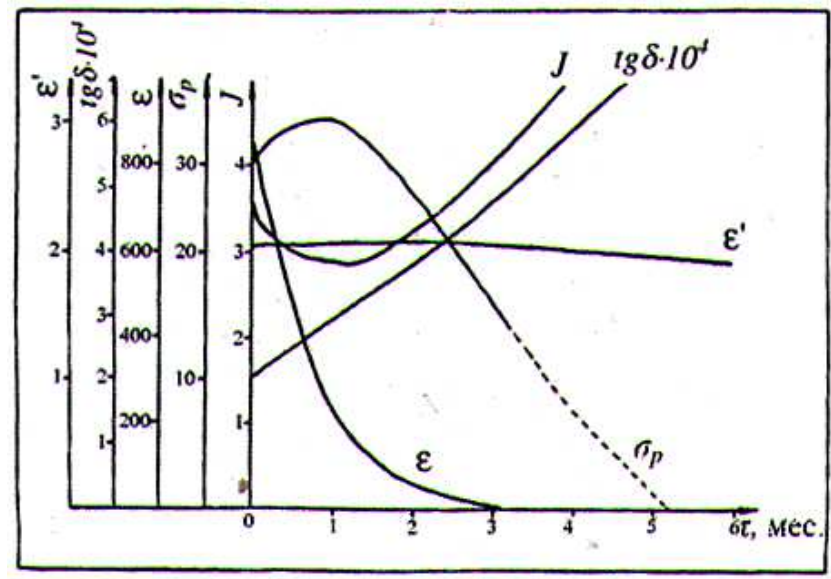

Figure 1. Change in the properties of HDPE in the process of atmospheric aging.

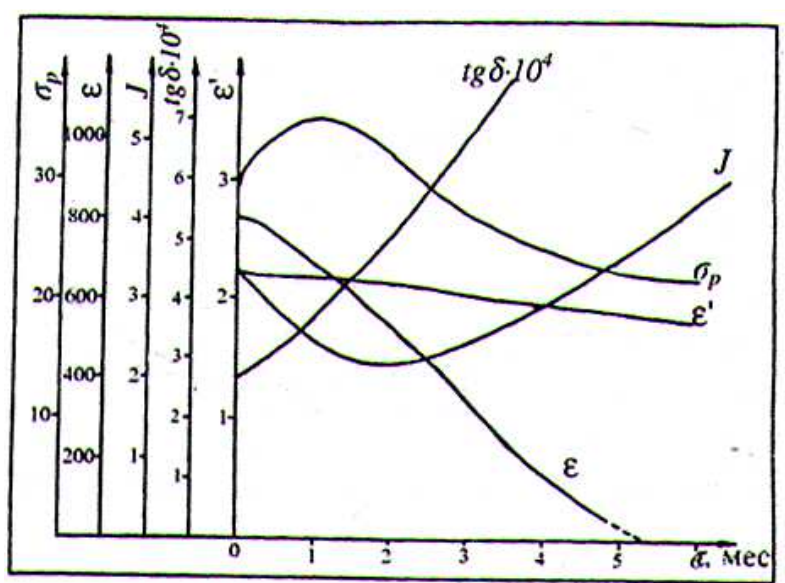

Figure 2. Atmospheric aging of HDPE, stabilized with a mixture of amines. 
The tensile strength, as in the case of unstabilized samples, first increases, reaching $32 \mathrm{MPa}$, and by the end of the first month of exposure in atmospheric conditions, and in the case of artificial aging, after 375 hours, significantly decreases.

With increasing exposure time, an increase in the $\mathrm{MM}$ mass of the polymer, controlled by the value of the melt index, was observed. In the process of aging, the tangent of the dielectric loss angle increases linearly, the permeability value drops somewhat, and the color changes from matte to dark yellow. All this testifies to the complexity of the oxidative processes taking place in the polymer under the influence of sunlight [11-14].

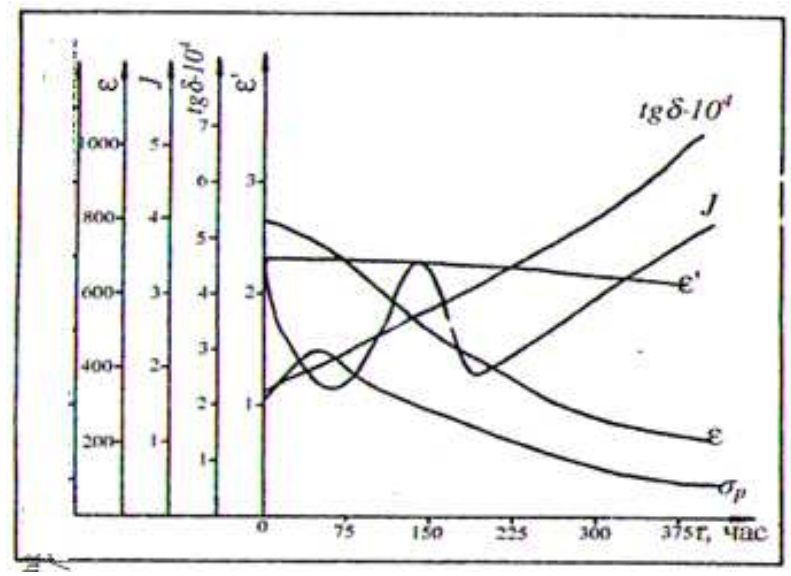

Figure 3. Artificial aging of HDPE, stabilized by thioalkophene.

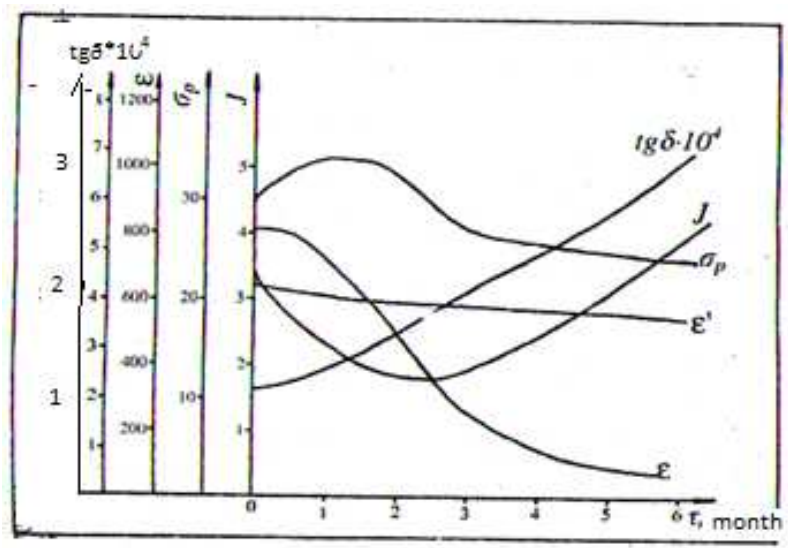

Figure 4. Atmospheric aging of HDPE, stabilized by thioalkofen-MBP.

Simultaneously, the effectiveness of using a mixture of amines to prevent the aging of HDPE was investigated. The results are shown in Figure 5.

The data obtained indicate a long-term preservation of dielectric parameters in the aging process.

When using a mixture of amines and thioalkofen MBP as stabilizers HDPE there is an effective stabilizing effect. The use of these stabilizers increases the stability of HDPE properties by $1.5-2$ times in atmospheric and in severe artificial aging conditions. However, a lower toxicity, a lower degree of polymer staining, and a lower value of $\operatorname{tg} \delta$ when the thioalkofen MBE is introduced into HDPE makes its use preferable to the use of a mixture of amines. Therefore, further in the development of composite materials, high density polyethylene was used, stabilized with thioalkophen MBE in an amount of $0.15 \%$ by weight.

HDPE after 100 hours exposure under UV irradiation completely loses its strength, elasticity and becomes brittle.

This is explained by destruction of the polymer chain and a decrease in MW, the appearance of the gel fraction, [ $\eta]$ soluble fraction of polyethylene after 200 hours of irradiation decreases from 1.6 to 0.6 . Relatively high resistance to UV irradiation is shown by HDPE containing stabilizing modifiers-diafen-HH (0.9), benzon-00 (1.25) and TU (1.25 mass\%), which is explained by the appearance of microoriented regions around the stabilizer particles and amplification of amorphous phase.

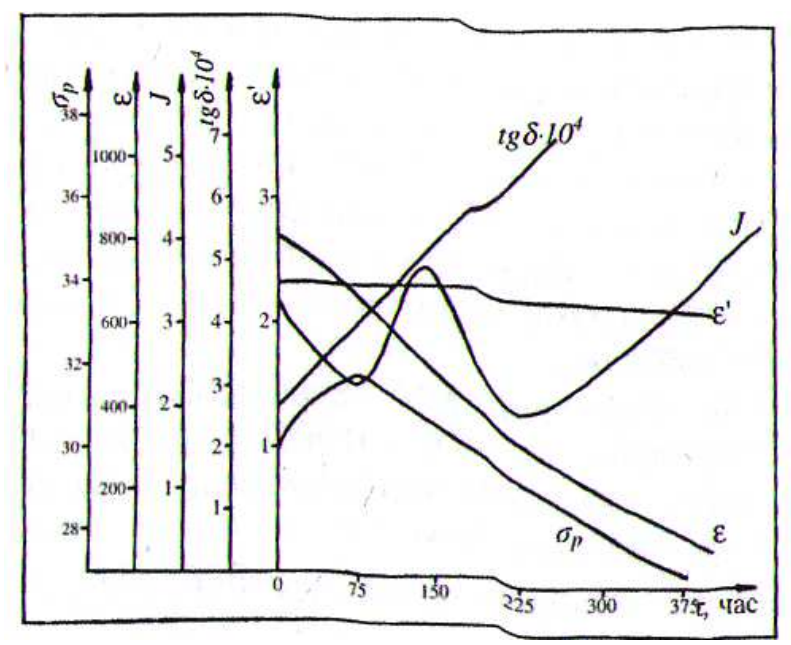

Figure 5. Artificial aging of HDPE, stabilized with a mixture of amines.

The introduction of stabilizers-diafen-HH, thioalkofenMBP and TU raises $T_{\text {melting }}$ and $T_{\text {decomposition }}$ HDPE, which is explained by the formation of a less defective fine-crystalline structure in the presence of stabilizers.

The destruction of high-molecular $(\mathrm{M} \eta \geq 2 \times 105)$ fractions in polyethylenes after $200 \div 500$ hours exposure under UV radiation disappears, which is explained by the intensive destruction of the polymer, but the content of the gel fraction also increases up to $40 \%$.

The processes of destruction and struktvurirovaniya occur not only in amorphous $(20 \div 25 \%)$, but also in the crystalline phase of polyethylenes.

The presence of the gel fraction is explained by the formation of a network structure due to the recombination of macroradicals.

In the presence of stabilizers, in particular, diphene-NN, as a result of dissociation of light energy by energy, which is not capable of causing chemical degradation of the polymer, partial destruction occurs.

In the melt mode in the process of step cooling, the rate of compaction at the association of small structures into more perfect and large ones occurs according to the established mechanism, regardless of the type of stabilizer.

Stabilizers diphene-NN, tialkofen-MBP and TU promote a sharp increase in specific volume HDPE and decrease in the 
density of the melt. HDPE containing these stabilizers over the entire temperature range have higher values of Vc. Stabilizers increase the rate of formation of crystallization centers (Tcr-124 $\div 128^{\circ} \mathrm{C}$ ), which is 90 minutes, initial HDPE-150, in the presence of benzene-00-130, TU-130 and tialkofena-120 minutes. In the presence of stabilizers, the induction period of crystallization is reduced to $6 \div 12$ minutes, the initial polyethylene is 12 minutes. The obtained results are of practical importance, since stabilizers, in particular, diphene-NN, increase the service life of polyethylene products, reduce the induction period of crystallization and the time of complete crystallization, accelerate the process of polyethylene processing, and significantly shorten the sample holding time in the mold.

The rheological characteristics of stabilized HDPE, in contrast to the initial HDPE in the presence of stabilizers, the viscosity of the melts decreases significantly, depending on the shear stress and decreases with increasing $\tau$. This is explained by the shape of the associates formed around the particles of the stabilizers and, in connection with this, some increase in the activation energy of the viscous flow of stabilized polyethylene indicates a cooperative displacement of the macromolecules.

HDPE stabilized by diaphene-NN, benzon-00 and tialkofen-MBP in motor gasoline swells slightly. Oil swelling occurs to a lesser degree, except for coal-coal oil, in which the swelling of the initial HDPE in 12 months reaches $8.4 \%$ in the presence of diaphene-HH, during this period, the swelling is $2.16 \%$.

The use of a mixture of amines and tialcophene MBE increases the stability of HDPE properties in the atmospheric and artificial aging conditions by a factor of 1.5 to 2 , which is explained by the phase reactivity of these stabilizers with the active macroradicals of the systems and their associative action. A lower degree of polymer colouring and a lower value of $\mathrm{g} \delta$ is achieved when tialcofen-MBP is added to HDPE in an amount of $0.15 \%$ by weight.

The thermoplastic elastomers of the "B" series were prepared by mechanically mixing the calculated quantities of HDPE and EPDM in a melt by rolling. In contrast to the existing methods for the production of thermoplastic elastomers of the "D" series (dielectric), they were obtained on the basis of HDPE and EPDM-60, synthesized under specific conditions: copolymerization of ethylene with propylene and vinylcyclohexene $(\mathrm{VCH})$ was carried out in the presence of catalysts of isozo- $\left(\mathrm{C}_{4} \mathrm{H}_{9}\right) \mathrm{AlCl}$ chloride and vanadium triacetyl acetone catalysts $\left(\mathrm{AC}_{3} \mathrm{~V}\right)$ at a temperature of $100^{\circ} \mathrm{C}$.

The resulting powdered crosslinked product had the following characteristics: propylene content, \% mol-47; content of IGCC, \% mol-1.1; cross-linking density, mol/1-10. The composition based on cross-linked $\mathrm{VCH}$ of ethylenepropylene elastomer $(\mathrm{EPDM}+\mathrm{VCH})$ and polyethylene was prepared similarly to the $\mathrm{A}$ and $\mathrm{B}$ thermoplastic elastomers.

The exclusion from the composition of the polar activators in this case, such as sulfur-containing and peroxide compounds, leads to an improvement in the dielectric characteristics of polyolefin thermoplastic elastomers.

Figures 6 7and 8 show IR spectra of high-density polyethylene, ethylene-propylene terpolymer (3rd component-ethylidene-norbornene) and thermoplastic elastomers based on them, containing various amounts of HDPE in the composition.

The carbon-carbon bond of the polymer chain represents an absorption band at $1100 \mathrm{~cm}^{-1}$. Information on the lateral methyl branches carries an absorption band at $1378 \mathrm{~cm}^{-1}$ and the total number of branches per 1000 carbon atoms calculated for HDPE was only 4-7, while for the EPDM they are about 200-300, i.e. many times more. In the initial HDPE, along with the alkyl branching, there is a small amount of unsaturated vinyl $\left(910 \mathrm{~cm}^{-1}\right)$ and vinylidene $\left(3020-3010 \mathrm{~cm}^{-1}\right)$ bonds. The presence of the crystalline phase was fixed by the doublet of the bands $720-731 \mathrm{~cm}^{-1}$. The determination of the ratio of the integral absorption values of the two components of the doublet of the given polymer for the estimation of the degree of crystallinity was not carried out by us because of the large measurement error in comparison with the $\mathrm{x}$-ray phase method.

In the ethylene-propylene elastomer of EPDM-60 there is a band of pendulum vibration of the $\mathrm{CH}_{2}$ group at $720 \mathrm{~cm}^{-1}$, while the absence of the doublet $720-731 \mathrm{~cm}^{-1}$ indicates its amorphousness. The amount of propylene in the chain was characterized by the intensity of the band $1378 \mathrm{~cm}^{-1}$. The presence of a diene in the polymer chain is indicated by a band in the $3045 \mathrm{~cm}^{-1}$ region.

For TEP, a decrease in the intensity of the absorption bands inherent in the initial elastomer is noted, but a disproportionate change in these characteristics allows us to note some important results.

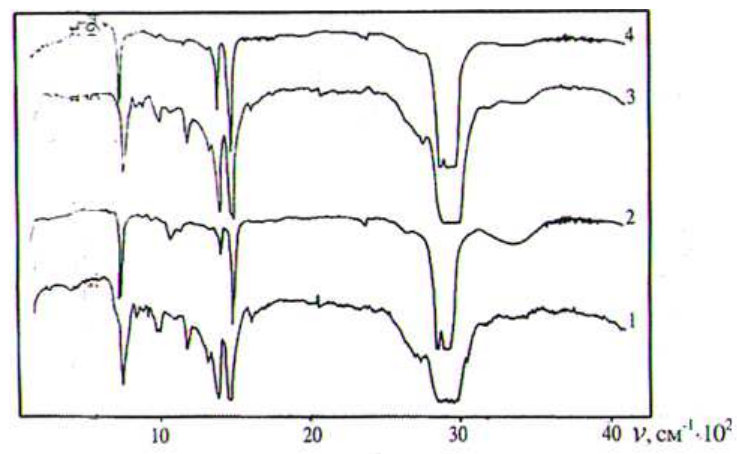

Figure 6. IR spectra of HDPE (2), EPDM (1), and thermoplastic elastomers of series ' $A$ ' (3) and ' $D$ ' (4).

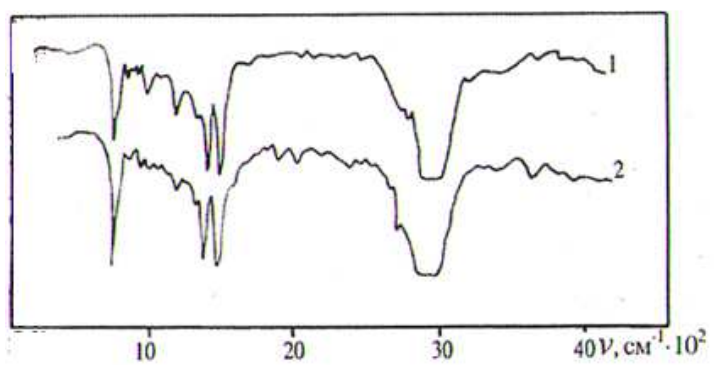

Figure 7. IR spectra of TEP series ' $B$ ' (1) and ' $D$ ' (2), subjected to boiling xylene treatment. 
With an increase in the elastomer content in TEP, its characteristic absorption bands at 720, 620, 870, 930, 1150, $1380,1460,70,2725,3180,4250$ and $4310 \mathrm{~cm}^{-1}$ increase in intensity, however, the reverse estimated calculations of the EPDM content in TEP's intensity of the absorption bands of the propylene unit, does not correspond to its practical content. In addition, the observed weakening of the band at $690-900 \mathrm{~cm}^{-1}$, which refers to the end vinylidene groups $>\mathrm{C}=\mathrm{CH}_{2}$ in EPDM, combined with a disproportionate change in the band at $1150 \mathrm{~cm}^{-1}$ indicates chemical transformations during the preparation of the TEP.

The very small fraction of the uncertainty in all TEP series is evidenced by the absorption in the region of $1580 \div 1800$ $\mathrm{cm}^{-1}, 3020 \div 3010 \mathrm{~cm}^{-1} .1000 \mathrm{~cm}^{-1}$. The IR spectra of the Tseries of the ' $B$ ' series show that in this case a simple superposition of the spectra characteristic of the initial polymer components i.e. the presence of a mechanical mixture is observed, while the TEPs of the ' $\mathrm{B}$ ' and ' $\mathrm{D}$ ' series are observed to convert the $980 / 960 \mathrm{~cm}^{-1}$ singlet at $980 \mathrm{~cm}^{-1}$, which indicates the interaction of the elastomeric phase over the double bonds during the modification process. For the
TEP of series 'A', a strong absorption of the $1378 \mathrm{~cm}^{-1}$ band characterizing the number of $\mathrm{CH}_{3}$-groups is observed.

The appearance of alcohol bands of $\mathrm{CH}$ groups at 3370 , $1040,1120 \mathrm{~cm}^{-1}$ is also observed, which are probably the result of interaction of polymer components with MPC and indicate that partial interaction between the elastomer and the polyethylene phase occurs in the TEP of series ' $A$ '. To confirm this assumption, TICs have been treated with boiling xylene, which is the selective solvent of the crystalline phase of the polyolefin.

For TEPs of series B and D after aging in boiling xylene, almost complete removal of the polyethylene crystalline phase from the elastomer matrix is observed, which indicates that there is no chemical interaction between the polymer components. In the TEP series A, even after prolonged exposure to boiling xylene, it was not possible to completely remove the polyethylene phase, which indicates partial interaction of the initial polymer components during the modification process, increasing the MPC concentration leads to a decrease in the fraction of the extracted amount of $\mathrm{PE}$ in the boiling xylene (Table 4).

Table 4. The amount of extracted HDPE after holding TEP in boiling xylene for after 72 hours.

\begin{tabular}{|c|c|c|c|c|c|}
\hline \multirow{2}{*}{ Namme } & \multicolumn{3}{|c|}{ TEP series A amount of peroxide } & \multirow{2}{*}{ 'B' series TEP } & \multirow{2}{*}{ 'D' series TEP } \\
\hline & $\mathbf{0 , 2}$ & 0,8 & 1,0 & & \\
\hline The amount of PE extracted from TEP, $\%$ by mass. & 97 & 90,7 & 81,6 & 100 & 100 \\
\hline
\end{tabular}

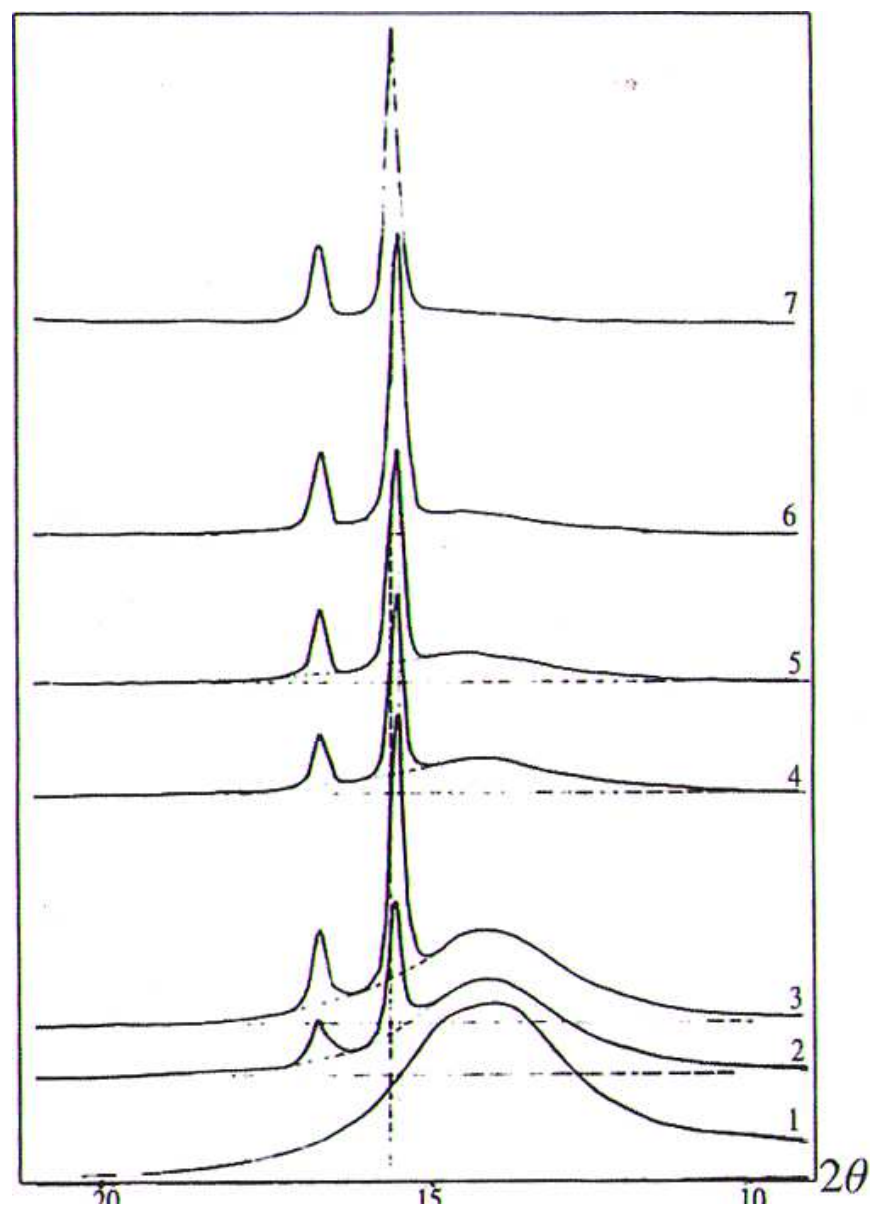

Figure 8. Diffraction curves of the initial EPDM-E (1) and HDPE (7) and thermoplastic elastomers 'A'-series containing 10, 20, 30, 40 and 50\% HDPE (respectively $2 \div 6$ ); $1 \div 3$ at $200 \mathrm{imp} / \mathrm{s}, 4 \div 7$ at $400 \mathrm{imp} / \mathrm{s}$. 
Thus, the IR spectroscopic data allow us to conclude that, in contrast to the mechanical mixture, TEP, under the action of modifiers, chemical transformations occur in the elastomeric matrix, and in TEPs of the ' $\mathrm{B}$ ' and ' $\mathrm{D}$ ' series, these transformations do not affect the polyethylene phase. In the TEP of the ' $A$ ' series, both polymeric components enter into the interaction with the modifier (dicumyl peroxide), which allows one to conclude that partial PE grafting to the elastomer.

The crystalline phase in the TEP was studied by X-ray diffraction. The degree of crystallinity decreases monotonically with increasing volume fraction of the elastomeric component for all series of TICs. On the diffraction curves (Figure 8) of the A, B and D series samples, in contrast to the 'B'-series (mechanical mixture) samples, a certain shift of the diffraction reflections of the polyethylene component toward smaller angles occurs. In addition, the diffraction reflexes broaden, which in combination with the observed shift allows us to conclude that in the synthesis of TICs of series A, B, and D, an elementary crystal cell of PE is distorted. The performed calculation of the parameters "a", "b" and "c" of the crystal cell of these TEPs (Table 5) confirms the above assumption.

It should also be noted that with the increase in the content of the elastomeric phase, the overall background of the amorphous halo grows on the diffractogram, however, there is a tendency for it to narrow and increase its maximum position along the intensity scale, that is, in the arrangement of disordered HDPE molecules and elastomer, "Short-range order," perhaps, due to the formation of sub segmental microorganisms. This, in turn, indicates a greater degree of structural disorder of the TIC in comparison with the mechanical mixture-TEP of the ' $\mathrm{B}$ ' series.

Table 5. The effective sizes of crystallites and the parameters of a crystalline cell of polyolefin TEP.

\begin{tabular}{|c|c|c|c|c|c|}
\hline \multirow{2}{*}{ TEP series } & \multirow{2}{*}{ Degree of crystallinity, \% } & \multirow{2}{*}{ The effective size of the crystallites $L, A^{\prime}$} & \multicolumn{3}{|c|}{ The unit cell parameters, $A^{\prime}$} \\
\hline & & & $\mathbf{a}$ & B & c \\
\hline $\mathrm{A}$ & 40 & 202 & 7,41 & 4,943 & 2,53 \\
\hline B & 42 & 202 & 7,42 & 4,943 & 2,53 \\
\hline $\mathrm{D}$ & 41 & 200 & 7,42 & 4,942 & 2,53 \\
\hline $\mathrm{C}$ & 40 & 170 & 7,42 & 4,972 & 2,53 \\
\hline
\end{tabular}

Direct studies of the morphological features of the TEPs studied were carried out by electron microscopy. This allowed us to visually assess the degree of heterogeneity and reveal the nature of supramolecular formations in TEP.

From the above-mentioned electron micrographs, for all the investigated series of TEPs, a characteristic formation of a typical heterophase system is evident. An increase in the degree of crystallinity in the TEP leads to the formation of spherulite structures with diffusion boundaries. It should be noted that the TEP series A and the mechanical mixture (' $\mathrm{B}$ ' series) are more homogeneous systems than the other types of polymers studied (Figure 9).

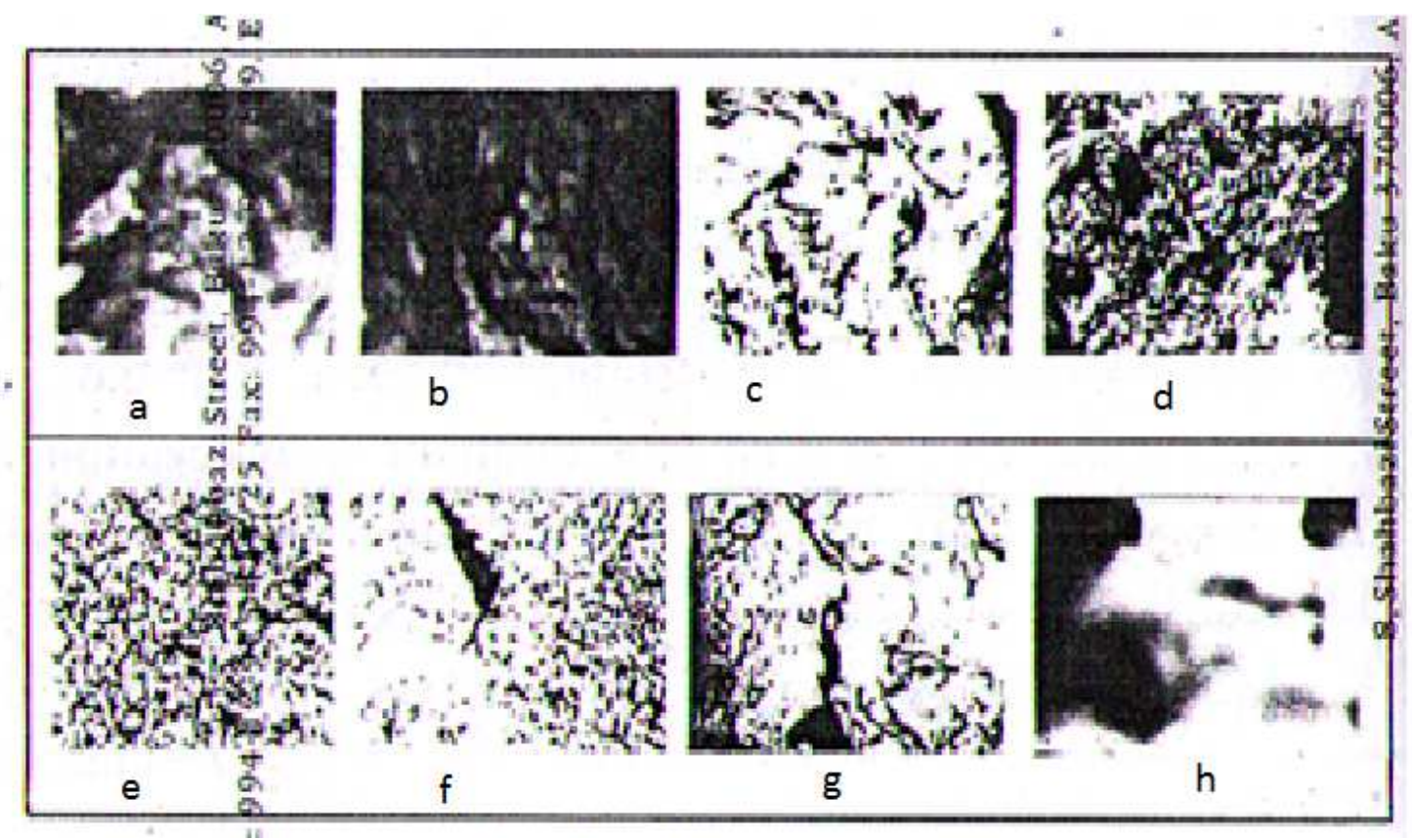

Figure 9. Electronic photomicrographs of TEP series A with HDPE content, mass\%: 40 (a) and 60 (b); Series B HDPE 40 (c) and 60 (d); Series D HDPE 20 (e), $40(f), 60$ (g) and B series HDPE 40 (h).

Electron microscopic data show that in the region of HDPE concentrations of about $60 \%$, the formation of polymer mixtures of a static nature is observed, which, unlike the mixtures of the matrix chaotactor, have an uneven 
distribution of one phase into the other with larger domain switches. Table 6 gives the dimensions of the domain inclusions in the TEP, determined by electron microscopy sampling. These data show that in the region of critical concentrations of the polyethylene phase $(50-60 \% \mathrm{w} / \mathrm{w})$, a considerable increase in the size of the domain inclusions is observed, which leads to loosening of the interphase layer of the elastomeric matrix. A further increase in the concentration of HDPE leads to the reversal of polymer phases, where the continuous phase-matrix is already a crystalline component, which leads to an increase in the density of molecular packagings.

Table 6. Effect of the composition of the thermoplastic elastomer series ' $D$ ' on the degree of crystallinity and the dimensions of heterogeneous microregions.

\begin{tabular}{|c|c|c|c|c|c|}
\hline \multirow{2}{*}{$\begin{array}{l}\text { HDPE content in } \\
\text { TEP, \% wt. }\end{array}$} & \multirow{2}{*}{$\begin{array}{l}\text { Degree of } \\
\text { crystallinity, \% }\end{array}$} & \multirow{2}{*}{$\begin{array}{l}\text { The effective size of the } \\
\text { crystallites } L, A^{\prime}\end{array}$} & \multicolumn{3}{|c|}{ The sizes of heterogeneous inclusions, $\mathbf{A}^{\prime}$} \\
\hline & & & Minimum & Medium & Maximum \\
\hline 20 & 18 & 150,3 & $30-40$ & 200 & 350 \\
\hline 30 & 26 & 161,5 & $35-40$ & 420 & 750 \\
\hline 40 & 40 & 169,0 & $35-45$ & 500 & 900 \\
\hline 50 & 47 & 180,2 & $45-50$ & 900 & 1700 \\
\hline 60 & 54 & 192,0 & $45-50$ & 1200 & 2700 \\
\hline
\end{tabular}

The DTA results of the TEPs under study are in good agreement with the above data. Demi-HDPE according to DTA is $136^{\circ} \mathrm{C}$. Ethylene-propylene elastomers do not have a definite value due to the amorphous structure. According to DTA, as the content of the amorphous phase of the elastomer in the TEP increases, the areas of melting peaks decrease. The melting of crystalline domains in the matrix of elastomers in TEPs of series 'B' and 'D' occurs at a temperature of $2 \div 30^{\circ} \mathrm{C}$ lower than that of the initial HDPE, which is characteristic for mechanical mixtures and indicates the absence of interaction between the polymer components. The TEP of series A recorded a sharper fall in the Tcl of crystalline domains in the elastomer matrix $\left(\mathrm{Tm}=126^{\circ} \mathrm{C}\right)$; which indicates a partial interaction between the initial polymer components. A certain increase in the oxidation effect is also observed with the formation of hydroperoxide groups and a decrease in the exo-effect, which prevents the destruction of the sample. For the TEP of the 'D' series, the oxidation process is characterized by a low intensity with a maximum of the exoeffect at $295^{\circ} \mathrm{C}$. A more intense exoeffect with a maximum at $280^{\circ} \mathrm{C}$ is observed for the mechanical mixture, and the exothermic thermo-oxidative degradation occupies an intermediate position between the initial polymer components and has a maximum at $420^{\circ} \mathrm{C}$.

Mass losses change in the following sequence: TEP series $\mathrm{D}<$ TEP series $\mathrm{B}<$ TEP series $\mathrm{A}$. DTA data in combination with the results of IRS show that the presence of by-products of the decomposition of modifiers leads to a decrease in the resistance to thermal oxidative destruction of TEP, for example a sample of the A series. incompatibility of HDPE and EPDM, which is obviously caused by differences in the formation of final TEP structures, under conditions of their production (Figure 10).

To estimate the degree of inhomogeneity, a technique was used that takes into account that $\omega$ for extremely inhomogeneous compositions is proportional to the volume fraction $\mathrm{V}$ of the crystalline component $\omega=\omega v=1$ (V). Extremely homogeneous mixtures at $\mathrm{V}=$ const have a lower degree of crystallinity, and the more consistently the more homogeneous the composition, the more complex the process of crystallization.

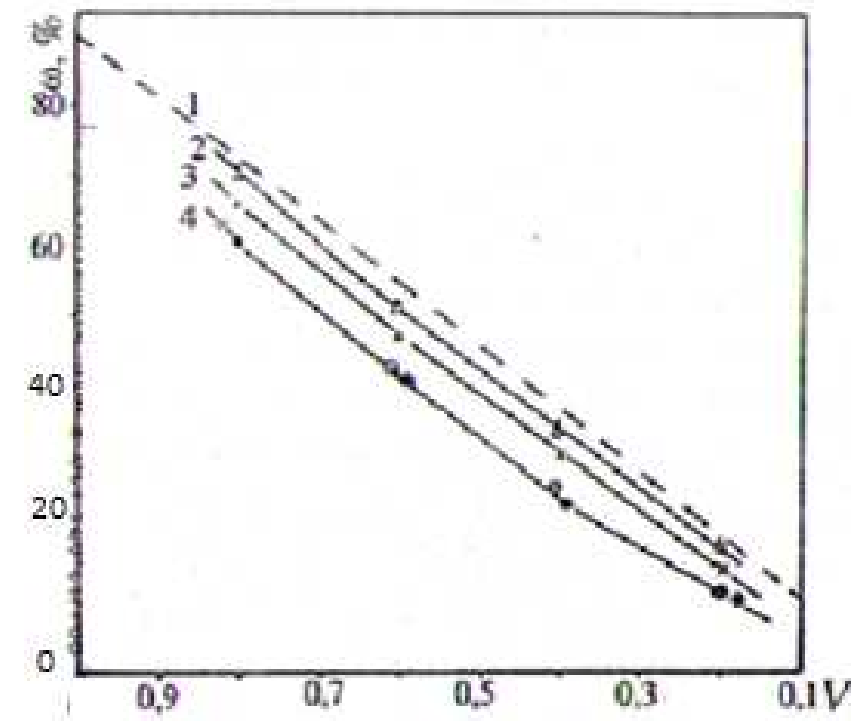

Figure 10. Comparison of the experimental dependences of the degree of crystallinity $\omega$ on the volume fraction of HDPE in the TEP of the series $A$ (4), $B$ (3), $C$ (4) and D (2) with a relatively limiting theoretical dependence (1).

Comparing the values of the experimental curve $\omega=\omega(\mathrm{V})$ with respect to the limiting theoretical values, one can judge the degree of compatibility of the compositions under study. From the degree of heterogeneity, polyolefin TEPs can be arranged in the following series: $\mathrm{D}>\mathrm{B}>\mathrm{A}$.

It follows from the above studies of the TEP structure that this polymer system is characterized by a heterogeneity of a higher order than simple mechanical mixtures. Depending on the method of production, the TEPs differ somewhat, the D and B samples being the most heterogeneous. Samples of the A series occupy an intermediate position between them and the mechanical mixture.

The different degree of heterogeneity of the above polymer systems necessitates a more detailed consideration of the compatibility of the initial components on the basis of which TEPs are formed. Thus, in the process of studying the properties of a large series of mixtures of polymers, it was shown that the compatibility factor has a significant effect on the phase state of the system under investigation 
[14-16].

From the point of view of thermodynamics, a stable singlephase system is characterized by a decrease in the isobaricisothermal potential $(\Delta \mathrm{G}<\mathrm{O})$ and is described by the wellknown equation:

$$
\Delta \mathrm{G}=\Delta \mathrm{H}-\mathrm{T} \Delta \mathrm{S}
$$

where $\Delta \mathrm{H}$ is the enthalpy change, $\Delta \mathrm{S}$ is the entropy change. In view of the smallness of the $T \Delta S$ value, the evaluation of the state of the structure of polymer systems is characterized by $\Delta \mathrm{H}$, where the negative values $(\Delta \mathrm{H}<\mathrm{O})$ correspond to the compatibility of the polymers.

It is practically very difficult to determine $\Delta \mathrm{G}$ by direct methods in the process of polymer displacement, and therefore the degree of compatibility is determined indirectly by the interaction parameter $\mathrm{h}$, which is defined as:

$$
\mathrm{h}=\mathrm{V}_{\mathrm{S}} / \mathrm{RT}\left(\delta_{1}-\delta_{2}\right)^{2}
$$

where, $\mathrm{h}$ is the Hildenbrand interaction parameter, $\delta_{1}$ and $\delta_{2}$ are the solubility parameters of the components being mixed, and $\mathrm{V}_{\mathrm{S}}$ is the volume of the mixtures [56].

Calculation of solubility parameters for HDPE and EPDM compositions leads to the following values:

$$
\Delta_{\mathrm{HDPE}}=\delta_{\mathrm{EPDM}}=0,81\left(\mathrm{cal} / \mathrm{sm}^{3}\right)^{0,5}
$$

Despite the equality of the solubility parameters for these polymers, due to the specificity of their structure, thermodynamic incompatibility can be observed, since the gain of entropy as a result of mixing of two dissimilar molecules compensates for the energy expenditure on the destruction of supramolecular structures and intermolecular bonds in the original components. Thus, the complexity of the molecular structure of polymers makes it difficult, in this case, to apply thermodynamic criteria in assessing the degree of compatibility, as a result of which an attempt was made to apply relaxation spectrometry.

\section{Discussion}

\subsection{Temperature Dependence of the Mechanical Loss Tangent in HDPE}

When combined, intensive processes of thermal mobility occur, causing the greatest dissipation of energy. In particular, the vitrification process is more intensive, i. e. $\alpha$ process of segmental mobility. The manifestation of relaxation regions associated with segmental mobility, makes it possible to uniquely determine whether these polymer systems are homogeneous or heterogeneous. The presence in the complex binary polymer mixtures of the two main relaxation regions, vitrification, indicates the heterogeneity of the system, while the existence of one main glass transition region indicates its homogeneity [17-24].

We have obtained the temperature dependences of the tangent of the angle of mechanical losses for several frequencies by the forced oscillation method. These spectra for HDPE and a similar picture of losses in the regime of forced resonance oscillations are shown in Figures 11-12.

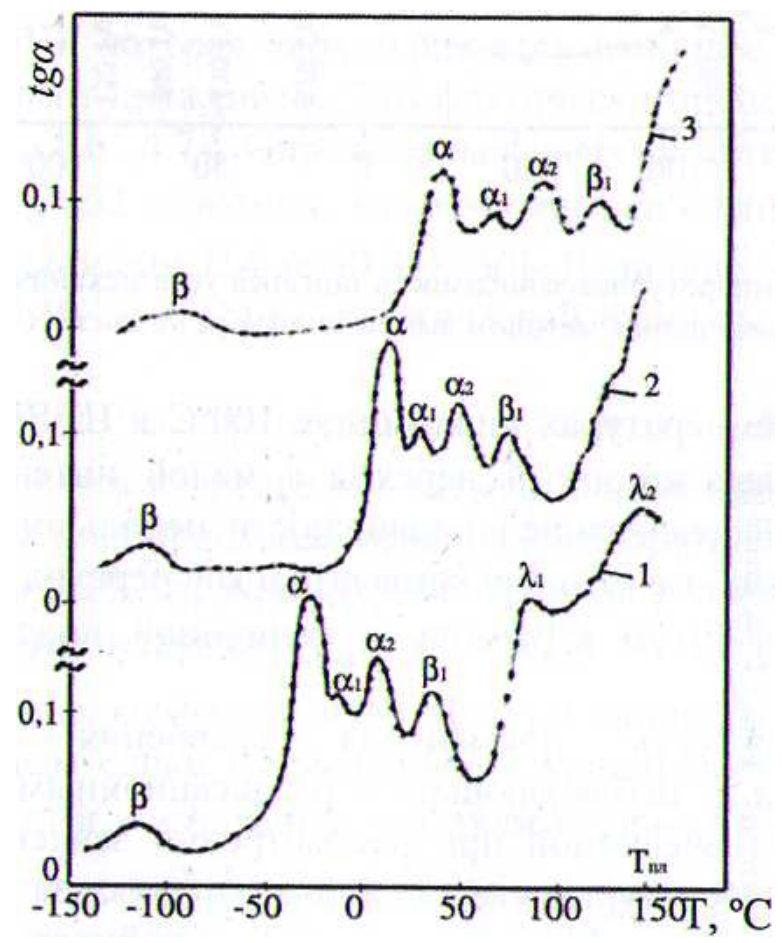

Figure 11. Temperature dependence of the tangent of the angle of mechanical losses in HDPE at a frequency of $2 \mathrm{~Hz}(1), 10 \mathrm{~Hz}$ (2) and 1000 $\mathrm{Hz}$ (3).

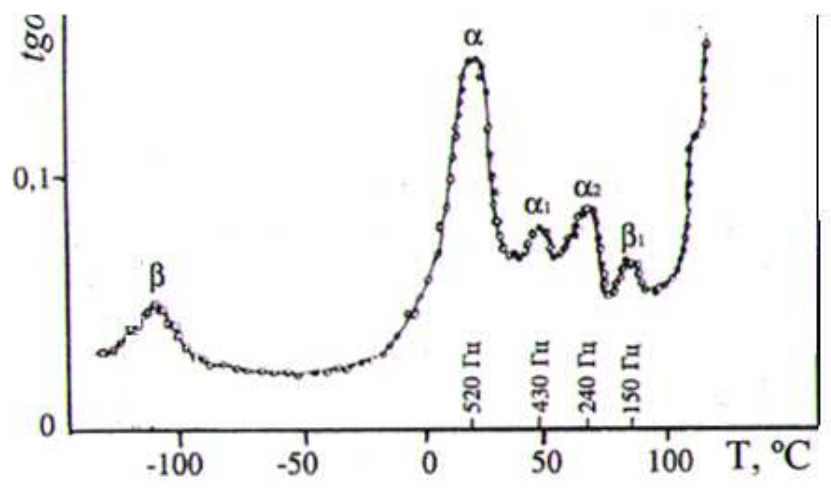

Figure 12. The temperature dependence of the tangent of the angle of mechanical losses of HDPE, obtained by the method of forced resonance oscillations.

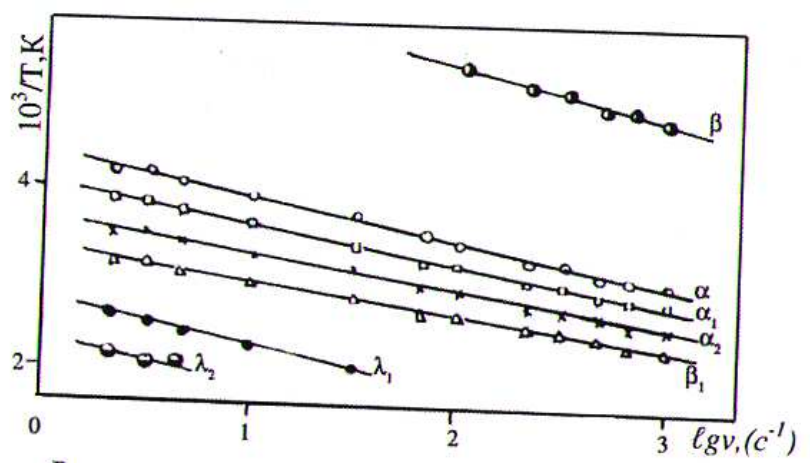

Figure 13. Dependence between the inverse temperature of the relaxation transitions in HDPE and the frequency. 
At temperatures below minus $100^{\circ} \mathrm{C}$, a $\beta$-relaxation transition with a low intensity due to the mobility of small structural units is observed in HDPE. this is a small-scale transition with an activation energy of $29 \div 30 \mathrm{~kJ} / \mathrm{mol}$ and a pre-exponential value of $\mathrm{B}_{\mathrm{i}}=1.6 \times 10^{-12} \mathrm{~s}$.aaaa

The next temperature relaxation- $\alpha$ transition is associated with segmental mobility in the amorphous phase of PE, which is characterized by the most intense thermal motion. This is actually the process of vitrification (Figures 11, 12). The specific activation energy is $\mathrm{U}_{\alpha}=52 \mathrm{~kJ} / \mathrm{mol}$, which practically coincides with the known data $[14,24]$. The value of the pre-exponential is $\mathrm{B}_{\mathrm{i}}=1.6 \times 10^{-12} \mathrm{~s}$. and the volume of the kinetic unit is $v=10^{-21} \mathrm{~cm}^{3}$ (Table 7).

The next two processes, i.e. $\alpha 1$ and $\alpha 2$-processes in HDPE belong to the $\alpha$-segmental mobility group, since for all these processes the kinetic unit is the segment $/ \mathrm{B}_{\mathrm{i}}=5 \times 10^{-12} \mathrm{~s}$. The characteristic relaxation times of these processes differ $\left(\tau_{\alpha}<\tau_{\alpha 1}<\tau_{\alpha 2}\right)$ due to the difference in the temperature coefficients. These processes refer to transition layers from the amorphous and crystalline phase ( $\alpha 1$-process) and to amorphous regions of spherulite fibrils, i.e. crystalline phase ( $\alpha 2$-process), the reason for the multiplicity of the $\alpha$ - transition in polyethylene is, first of all, the complexity of the morphological structure that causes differences in energy conditions and changes in the freedom of segments.

$\mathrm{B}_{\mathrm{i}}$-processes small-scale mobility in the crystalline phase. Three slow relaxation $\lambda_{\mathrm{i}}$ transitions (Figures 14, 15) with an activation energy of $49 \mathrm{~kJ} / \mathrm{mol}$, i.e., were detected by the voltage relaxation method in HDPE. close to the activation energy of the viscous flow of HDPE. Dimensions of kinetic units are presented in (Table 7).

The internal friction spectra of the EPDM-60 epylenepropylene elastomer, weakly cross-linked to retain the MPC form (a), sulfur-containing components (b) and vinylcyclohexene (c) (Figure 16) were obtained.

Area of manifestation and mechanism $\beta$-process in the elastomer is similar to that studied in HDPE. The activation energy $(\alpha)$ of transitions for ethylene-propylene elastomers, regardless of the type of cross-linking, is $47-49 \mathrm{~kJ} / \mathrm{mol}$ (Table 8 ). The main structural unit of this process is a free segment with average sizes of $30 \div 40 \mathrm{~A}^{*}$ and a volume in the order of $10^{-21} \mathrm{~cm}^{3}$, which indicates the generality of segmental mobility in EPDM with other elastomers.

Table 7. The characteristics of the relaxation transitions in HDPE, determined from the totality of the oscillations.

\begin{tabular}{|c|c|c|c|c|c|c|c|}
\hline \multirow{2}{*}{$\begin{array}{l}\text { Relaxation } \\
\text { period }\end{array}$} & \multicolumn{3}{|c|}{ Activation energy, $\mathrm{kJ} / \mathrm{mol}$} & \multirow{2}{*}{$\begin{array}{l}\text { coefficient } \\
\mathbf{B}_{\mathrm{i}}{ }^{* *}, \mathrm{~s}\end{array}$} & \multicolumn{3}{|l|}{ Kinetic unit } \\
\hline & $\mathbf{a}$ & $\mathbf{b}$ & c & & Volume, $\mathrm{V}_{\mathrm{K}}, \mathrm{sm}^{3}$ & Average linear dimension, $\mathrm{A}^{*}$ & Structural representations \\
\hline$\beta$ & 30 & 29 & - & $1,6 \times 10^{-13}$ & $2 \times 10^{-22}$ & $5-7$ & Several $\mathrm{CH}_{2}$ groups \\
\hline$\beta_{1}$ & 68 & 67 & - & $1,6 \times 10^{-13}$ & $2 \times 10^{-22}$ & $5-7$ & $-\ll-$ \\
\hline$\alpha$ & 52 & 51 & - & $5 \times 10^{-12}$ & $10^{-21}$ & $30-40$ & 20-25 groups $\mathrm{CH}_{2}$ (segment) \\
\hline$\alpha_{1}$ of glassification & 54 & 54 & - & $5 \times 10^{-12}$ & $10^{-21}$ & $30-40$ & Segment \\
\hline$\alpha_{2}$ & 59 & 60 & - & $5 \times 10^{-12}$ & $10^{-21}$ & $30-40$ & Segment \\
\hline$\lambda_{1}$ & 48 & 48 & 49 & $5,2 \times 10^{-8}$ & & & Physical node (microblock) \\
\hline$\lambda_{3}$ & - & - & 49 & $5,1 \times 10^{-6}$ & & & $-\ll-$ \\
\hline
\end{tabular}

A-stimulated oscillations, b-resonant oscillations, c-relaxation of voltage ** точность определения $\mathrm{U}( \pm 0,5+0,8 \mathrm{~kJ} / \mathrm{mol}) ; \mathrm{B}_{\mathrm{i}}( \pm 20 \%)$.

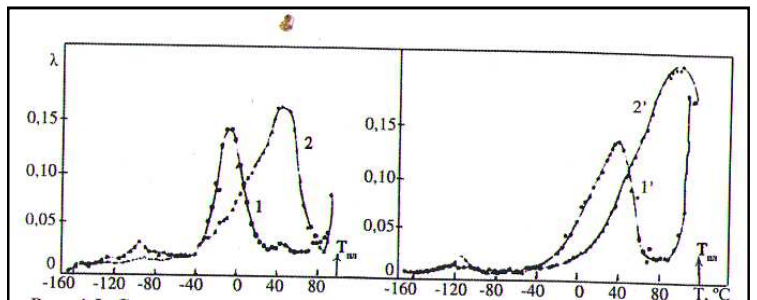

Figure 14. Spectra of internal friction for LDPE with different degrees of crystallinity: $1-0.62 ; 2-0.56 ; 1$ '-0.50; 2'-0.44.

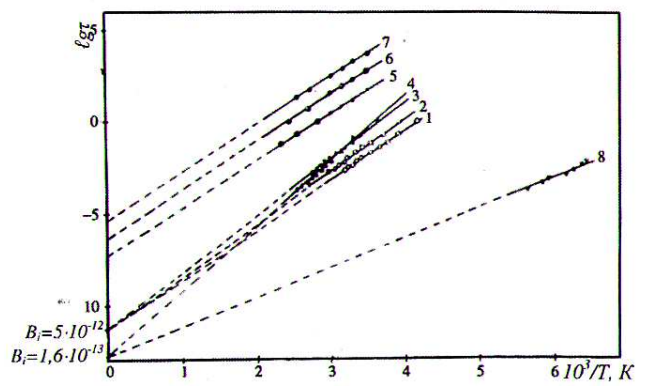

Figure 15. Dependence of the relaxation times of slow $\left(\lambda_{i}\right)$ and fast relaxation $(\alpha)$ transitions in HDPE on the inverse absolute temperature (according to Table 7).

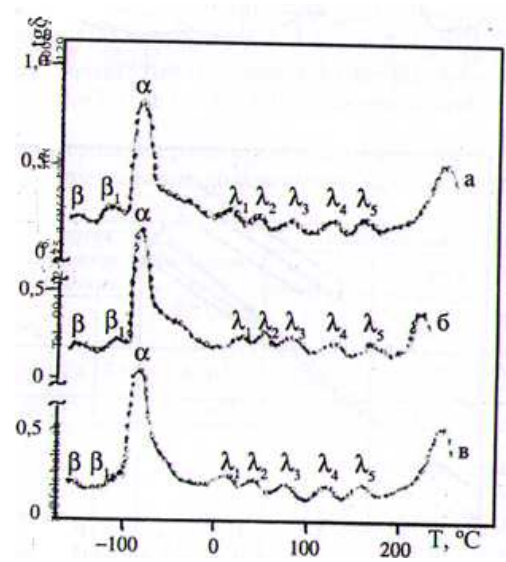

Figure 16. Spectra of internal friction of ethylene-propylene elastomer crosslinked with dicumyl peroxide (a), sulfur-containing components (b) and vinylcyclohexene (c) $1 \mathrm{~Hz}$.

In the region of higher temperatures, $\delta$ s and $\delta c$ processes are observed in the elastomeric matrix, depending on the type of cross-links. Process $\delta$ s-is characteristic of sulfide crosslinks and has an activation energy of $130 \mathrm{~kJ} / \mathrm{mol}$. (EPDM, cross-linked with sulfur-containing compounds). The process of $\delta$ c-relaxation refers to the chemical relaxation of 
transverse bonds of the "C-C" type, characterized by an activation energy of 150-152 kJ/mol, observed in the EPDM, crosslinked MPC and IGCC.

In the region of higher temperatures, $\delta \mathrm{s}$ and $\delta \mathrm{c}$ processes are observed in the elastomeric matrix, depending on the type of cross-links. Process $\delta$ s-is characteristic of sulfide cross- links and has an activation energy of $130 \mathrm{~kJ} / \mathrm{mol}$. EPDM, cross-linked with sulfur-containing compounds). The process of $\delta$ c-relaxation refers to the chemical relaxation of transverse bonds of the "C-C" type, characterized by an activation energy of $150-152 \mathrm{~kJ} / \mathrm{mol}$, observed in the EPDM, crosslinked MPC and VCH.

Table 8. Characteristic of relaxation transitions in the EPDM, crosslinked by MPC (a), sulfur-containing agents (b) and VCH (c).

\begin{tabular}{|c|c|c|c|c|c|c|c|c|c|}
\hline \multirow{2}{*}{$\begin{array}{l}\text { Relaxation } \\
\text { transition }\end{array}$} & \multicolumn{3}{|c|}{ Activation energy $U_{i}, \mathrm{~kJ} / \mathrm{mol}$} & \multicolumn{3}{|c|}{ Coefficient $\mathrm{B}_{\mathrm{i}}, \mathrm{C}$} & \multicolumn{3}{|c|}{ The size of the kinetic unit, $A$ * } \\
\hline & $\mathbf{a}$ & 6 & B & $\mathbf{a}$ & 6 & B & $\mathbf{a}$ & Б & B \\
\hline$\beta$ & 28 & 29 & 28 & $1,6 \times 10^{-13}$ & $1,6 \times 10^{-13}$ & $1,6 \times 10^{-13}$ & 5 & + & - \\
\hline$\beta_{1}$ & 40 & 42 & 41 & $1,6 \times 10^{-13}$ & $1,6 \times 10^{-13}$ & $1,6 \times 10^{-13}$ & 5 & + & - \\
\hline$\alpha$ & 45 & 46 & 45 & $5 \times 10^{-12}$ & $5 \times 10^{-12}$ & $5 \times 10^{-13}$ & 30 & + & 40 \\
\hline$\lambda_{1}$ & 46 & 46 & 45 & $1,1 \times 10^{-7}$ & $9,8 \times 10^{-6}$ & $1,0 \times 10^{-7}$ & 500 & 600 & 550 \\
\hline$\lambda_{2}$ & 46 & 46 & 45 & $9,3 \times 10^{-7}$ & $5,4 \times 10^{-6}$ & $8,5 \times 10^{-7}$ & 1000 & 1300 & 900 \\
\hline$\lambda_{3}$ & 52 & 53 & 54 & $8,4 \times 10^{-6}$ & $1,2 \times 10^{-6}$ & $1,7 \times 10^{-6}$ & 1200 & 1000 & 1200 \\
\hline$\lambda_{4}$ & 59 & 59 & 60 & $1,0 \times 10^{-7}$ & $9,3 \times 10^{-7}$ & $9,0 \times 10^{-7}$ & 900 & 1200 & 1100 \\
\hline$\lambda_{5}$ & 59 & 59 & 60 & $6,8 \times 10^{-7}$ & $6,3 \times 10^{-7}$ & $6,7 \times 10^{-7}$ & 2500 & 2200 & 2000 \\
\hline$\delta s$ & - & 132 & - & - & $8,2 \times 10^{-14}$ & - & - & $1-2$ & - \\
\hline$\delta c$ & 152 & - & 150 & $3,3 \times 10^{-14}$ & - & $3,3 \times 10^{-14}$ & $2-3$ & - & $2-3$ \\
\hline
\end{tabular}

\section{Conclusion}

The specificity of the structure that arises when highcrystalline HDPE-type polymers are added to the ethylenepropylene matrix and characterized, as already noted, by the presence of heterogeneity, leads to a drastic change in the relaxation properties of the polymer system as a whole.

Since the presence of the crystalline phase in the mixture significantly affects the entire complex of physic mechanical properties of similar polymer systems, TEPs were taken for comparison, which differed only in production methods, i.e. TEPs of various series containing $40 \%$ of the mass of polyethylene were taken.

The temperature dependences of the tangent of the mechanical loss angle of the TEC series $\mathrm{B}$ at various frequencies (from $5 \times 10^{-3} \mathrm{c}^{-1}$ to $10 \mathrm{c}^{-1}$ ) are presented. With increasing frequency, an unequal shift of the peaks of the manifested internal loss peaks to the right is observed on the temperature scale.

\section{References}

[1] Serenko O. A, Goncharuk G. P. et al. / Effect of temperature on the deformation behavior of a composite based on polypropylene and rubber particles // High Molecular Compounds.-2007.-No 1.- C. 71-78.

[2] Derikov I. Ya. Kutergina I. Yu. Et al. / Stable Nonequilibrium Composites Based on Liquid Crystal Polymers and Cadmium Selenide Nanoparticles // High Molecular Compounds. 2014. No. 4, p. 408-418.

[3] Zaikin A. E, Bobrov G. B. / Compatibilization of mixtures of incompatible polymers by filling // High-molecular compounds.-2012.-No. 8.-p. 1275-1282.

[4] Kuleznev V. N, Surikov P. V. // Phase equilibria in threecomponent polymer blends / High-molecular compounds.2012.-№11.-p. 1602-1609.

[5] Chalykh A. E, Gerasimov VK, Mikhailov Yu. M. Phase diagrams of polymer systems. M: Janus, 1998

[6] Mulder M. // Basic Principles of Membrane Technology. Dordrecht: Kluwer, 1996.

[7] Belov N. A., Safronov A. P., Yu. P. Yampolsky // Reverse gas chromatography and thermodynamics of sorption in polymers. / High-molecular compounds.-2012.-№11.-p. 1631-1647.

[8] Bundjali B., Yudistira I., JAriah B, Sukria L. // Study on properties of Polymer Blends from Polypropylene with Polycaprolactone and their Biodegradability / Polymer Journal, -2007-Vol. 39, No. 12.-pp. 1337-1344.

[9] Ermilova E. A, Sizova A. A, Il'icheva N. N., Pleshakov D. V. // Investigation of the thermodynamic compatibility of a threecomponent mixture of nitramines with a copolymer of methyl methacrylate and methacrylic acid. / Advances in Chemistry and Chemical Technology.-2014- No. 2.-p. 65-67.

[10] Rijhikova I. G., Volkov A. M., et al. Modification feature of binary mixtures PP / SKEP by the system of organic peroxidepolyfunctional vinyl monomer in the reaction extrusion process. Plastic masses, 8,2013 , p. 40-45.

[11] Murtazina L. I., Garifullin A. R., Nikultsev I. A., et all. Influence of plastificators on the property of unhardened hermetics on the basis of ethylene-propylendiene rubber. Engineer-chemist's encyclopedia, No. 8, 2014, pp. 31 - 35.

[12] Kirsh I. A., Pomogova D. A. Study of the properties of secondary polymer materials based on polypropylene and polyethyleneterephtalat, obtained in the influence of ultrasonic vibrations on the polymer melts. - Moscow, Plastic masses, 2012, No. 1, pp. 48-51.

[13] Kurbanova N. I. Heatelastolastics based on polypropylene and tri-etylene-propylene copolymer. Azerbaijan chemistry, - No. 1, - 2013, - P. 57-59.-2008-№4.-p. 69-72.

[14] Shastin E. R, Beknazarov H. S., Akhmedov W. K., Jalilov A. T.// Interphase interactions of three-phase polypropylene composite materials. / Universum. Technical sciences ./- 2018-№12.-p. 57.

[15] Shastin D. A., Wolfson S. I., Makarov T. V. // Influence of modification of triple ethylene-propylene rubber on the physicomechanical properties of rubbers. / Bulletin of Kazan Technological University.-2010-№4.-p. 5-7. 
[16] Ryzhikova I. G., Volkov A. M., Bauman N. A., Kazakov Yu. M., Wolfson S. I. // Influence of the concentration of the components of the modifying system peroxide / TMPTA and the Mooney viscosity of rubber SKEPT on the balance fluidity and impact resistance of master-batch SKEPT in a matrix of polypropylene. / Bulletin of the Technological University2015-No. 4.-from 148-150.

[17] Ryzhikova I. G., Volkov A. M., Bauman N. A., Kazakov Yu. M., Wolfson CB // Study of the physicomechanical properties of pp / skpt mixtures modified with peroxide and peroxide / tmpta system-Vestnik University of Technology. 2015. -№4. with. 134-137.

[18] Nurmeeva E. K. // Production and scope of ethylenepropylene rubbers SKEPT / -Vestnik of Kazan Technological University.-2012-p. 129-131.

[19] Prospects for the development of production of ethylenepropylene rubber // Production and use of elastomers. - 1998. №1. -WITH. 53-54.
[20] Klyuchnikov I. O., Klyuchnikov O. R., Stoyanov O. V. // Bulletin of Kazan Technological University.-2015.-№4 - p. 224-225.

[21] El-Sabbagh S. H. // Compability Study of Natural Rubber and Ethylene - Propylene - Diene Rubber Blends / Department of Polymers and Pigments, National Research Center, Dokki, Cairo, Egypt. 2001, p. 2-11.

[22] Askadsky A. A. // Influence of strong intermolecular and chemical interactions on the compatibility of polymers / Advances in Chemistry.-1999.-No. 4-p. 349-364.

[23] Amash A., Shuster R. H., Frueh T. // Effects of Compability in Rubber / Polypropilene Blends / Elastomere und Kunststoffe.2001.-No. 6-p. 315-320.

[24] Abou-Helal M. O., El-Sabbagh S. H. // Student on the Compability of NR-EPDM Blends Using Electrical and Mechanical Techniques / Journal of Elastomers and Plastics.2005.-No. 4.-p. 319-346. 